\title{
XVI.
}

Mittheilung aus der psychiatrischen und neurologischen Universitätsklinik (Prof. Carl Laufenauer) zu Budapest.

\section{Ueber die feineren pathologischen Veränderungen der Ammonshörner bei Epileptikern.}

\author{
Von \\ Dr. Ludwig Hajós, \\ em. I. Assistent der psychiatrischen und nenmologisehen Universitätsklinik zn Budapest.
}

(Hierzu Tafel XI. und XII.)

Das Studium der Epilepsie ist so alt, als die medicinische Wissenschaft. Unsere Kenntnisse von dieser Krankheit stammen von vier Quellen her: von klinischen Erfahrungen, von theoretischen Speculationen, Thierexperimenten und endlich von pathologisch-anatomischen Untersuchungen. Die ältesten Quellen sind die zwei ersten, welche eigentlich zu gleicher Zeit auf kamen: Hippocrates gab mit seiner ersten klinischen Beschreibung der Krankheit auch die erste der Epilepsietheorien, laut welcher der morbus sacer mit der Melancholie eine gemeinschaftliche Ursache habe, die, wenn sie den Körper befällt, Epilepsie, wem sie die Seele angreift, Melancholie hervorbringt.

Unsere Kenntnisse rühren ursprünglich aus diesen zwei Quellen her, zu denen sich mit der Zeit etwas anatomische Kenntnisse mischten, doch verursachten selbe nur Verwirrungen der reinen Abstraction und brachten recht romantische Anschaungen mit sich. So betrachtet Galenus als Krankheitsursache die Verdichtung der Gehiruflüssigkeit und den Verschluss der Gehirnventrikel; Helmontius findet die Ursache der epileptischen Anfälle in dem Toben eines im Hagen sitzenden "Archeus irritatus et quasi furibundus".

Unsere Kenntuisse von der Epilepsie kommen im ersten Viertel unseres Jahrhunderts mit einem bedeutenden Schritt nach vorwärts, 
da man in Folge der Section epileptischer Leichen und von Thierexperimenten so manches Neue fand. Schröder van der Kolk fand bei Epileptikern eine Hyperämie am Grunde des vierten Ventrikels und suchte darin die Ursache der Krankheit; Marschall-Hall (1863) meint auf Grund seiner Thierexperimente das Rückenmark an der Krankheit beschulden zu können. Die Untersuchungen von Schröder van der Kolk lenken das allgemeine Interesse auf das verlängerte Mark, da ganz bedeutende Autoren, so Kussmaul und Tenner, später auch Nothnagel experimentell obige Anschauung bestätigt finden; letzterer meint sogar, in der Varolsbrücke ein specifisches Krampfcentrum annehmen zu dürfen, dessen venöse Hyperämie die eplileptischen Anfälle auszulösen rermag.

Dem gegenüber localisiren Jackson, Ferrier, Fritsch, Hitzig, Luciani, Rosenbach und Unverricht auf Grund von Sectionsergebnissen und Vivisectionen die Ursache der Krankheit in die Gehirnrinde; Binswanger, Ziehen und Jolly meinen, dass die Anfälle verschiedene Ursprungsstätten haben. Bisher war die allgemein herrschende Ansicht, dass die epileptischen Anfälle durch den Reiz der motorischen Nervenelemente in der Gehirnrinde ausgelöst werden; Johannson (Inaugur.-Diss. Dorpat 1885. Ein exp. Beitr. z. Kenntniss der Ursprungsstätte d. epil. Anf.) und neuerdings Prus (Ueber die Leitungsbahnen und Pathogenese d. Rindenepilepsie. Wien. Klin. Wochenschrift 1898.) kommen auf Grund von Thierexperimenten zu dem Schluss, dass die Ursache der Anfälle in dem Reiz, der sensiblen Nervenendigungen innerhalb der motorischen Rindenregion zu suchen sei.

Während sich viele Autoren mit der Pathogenese der Epilepsie befassten, häufte sich ganz unbemerkt die Anzahl der anatomisch untersuchten Fälle, welche das Augenmerk in eine neue Richtung lenken.

Bouchet und Cazauvieilh (De l'epilepsie considereé dans des rapports avec l'aliénation mentale. Paris 1825) fanden zuallererst, dass bei Epilepsieleichen gar nicht selten das Ammonshorn der einen Seite härter, schmaler oder hyperämisch, bald wieder erweicht sei; da sie jedoch ähnliche Befunde auch bei verschiedenen Psychosen antrafen, schrieben sie der Sache keine Wichtigkeit bei.

Bergmann schreibt in den Hannöverschen Annalen von Holscher und Mühry, 1846, Folgendes: „Es ist mir sehr wahrscheinlich geworden, dass die Epilepsie mit der so oft vorkommenden Ungleichheit beider Ammonshörner, indem das linke häufig kleiner als das rechte oder umgekehrt gefunden wird, in Verbindung steht."

Bouchet giebt in einer später erschienenen Arbeit an (Annales medico-psychologiques, 1853), dass er unter seinen sämmtlichen patho- 
logisch-anatomischen Befunden am häufigsten die Induration des Ammonshorns angetroffen habe.

Foville findet häufig bei Epileptikern in der Gehirnrinde, insbesondere jedoch im Ammonshorn, Induration, Hyperämie und Gefässerweiterung.

Hoffmann (Allg. Zeitschr. für Psychiatrie, 1862) sucht.zwar den Grund der epileptischen Anfälle nicht im Ammonshorn, findet trotzdem häufig in Gehirnen von Epileptikern eine Induration dieses Organes; in zwei Fällen fand or sogar die Todesursache in capillaren Blutungen des Ammonshorns.

Bezüglich der Untersuchung der Ammonshörner sind die Arbeiten von Meynert epochemachend (Vierteljahrsschr. für Psychiatrie. Studien über das pathologisch-anatomische Material der Wiener Irrenanstalt, 1867); er schloss aus theoretischen Gründen (dass nämlich homolog gebaute Gewebe ähnlich functioniren) auf die Wichtigkeit der Ammonshörner in motorischer Hinsicht und sah eine Approbation dieser seiner Annahme in der häufig vorkommenden Alteration der Ammonshörner bei epileptischen Individuen. Obzwar er jedoch beinahe bei einem jeden Epileptiker eine Veränderung der Ammonshörner vorfand, schrieb er diesen Veränderungen die Ursache der Krankheit nicht zu, vielmehr hielt er sie für secundäre Erkrankungen: „eine Miterkrankung der Ammonshörner."

Seit Meynert's grundlegenden Arbeiten lenkt sich Aller Augenmerk immer mehr auf die Ammonshörner der Epileptiker. Charcot (Lecons sur les maladies du système nerveaux. Paris 1875) beschreibt bei Epilepsie die Veränderung der Ammonshörner und nach ihm kommt schon eine ganze Reihe von gesammelten Beobachtungen.

Sommer (Erkenntniss des Ammonshorns als ätiologisehes Moment der Epilepsie. Archiv für Psychiatrie, X. 1880) bringt 90 Epilepsiefälle, bei welchen er Veränderung des Ammonshorns vorfand und meint, dass die Alteration dieses Organes $30 \mathrm{pCt}$. aller epileptischen Fälle ausmache.

Holler (Bericht über die Niederösterr. Landesirrenanstalt, Ybbs 1872) obducirte vier Fälle von Epilepsie und fand bei einem jeden pathologische Ammonshörner.

Snell (Zur pathologischen Anatomie der Epilepsie. Allg. Zeitschr. f. Psychiatrie, 32) bringt den Sectionsbefund 100 Epileptiker und unter diesen beschreibt er nur in 3 Fällen eine entschiedene Veränderung der Cornua Ammonis.

Hemkes (Ueber Atrophie und Sclerose des Ammonshorns bei Epileptikern) schätzt auf 18 pCt. die Erkrankung der Ammonshörner. 
Pfleger (Beob. über Schrumpfung und Sclerose d. Ammonsh. bei Epilepsie. Zeitschr. f. Psychiatrie. Bd. 36) schätzt auf Grund von über 300 Obductionen auf $58 \mathrm{pCt}$. die Veränderung des Ammonshorns; in einer späteren Arbeit theilt derselbe Autor (Allg. Zeitschr. f. Psychiatrie, XXIV) die Autopsieen von 43 Epilepsiefällen mit: von diesen fand er bei 25 pathologisehe Ammonshörner.

Allenberger fand in $10 \mathrm{pCt}$. die Ammonshörner pathologisch; Bourneville schätzt auf Grund seiner Autopsieen in den Spitälern Salpêtrière und Bicêtre ebenfalls auf $10 \mathrm{pCt}$. die Veränderung dieses Organes; Gerhardt (Handb. der Kinderkr. Tübingen 1880) findet mit Meynert übereinstimmend bei seinen sämmtlichen Epilepsiefällen das Ammonshorn der einen oder anderen Seite erkrankt.

Während wir nun eine ansehnliche Zahl von Fällen beschrieben finden, wo bei Epileptikern eine makroskopische Veränderung der Ammonshörner mitgetheilt wird, finden wir relativ nur eine ganz geringe Zahl Arbeiten von den feineren, mikroskopisch sichtbaren Veränderungen dieses Organes.

In Allgemeinen scheint es mir auf Grund der mir. zur Gebote stehenden Fachliteratur, dass man die mikroskopischen Veränderungen der Ammonshörner bei Epilepsie erst nach dem Hinweis von Meynert anfing, zu untersuchen. Prof. Laufenauer fand in den siebziger Jahren bei vielen Epileptikern neben der makroskopischen Veränderung die Pyramidenzellenschichte entsprechend der Fascia dentata schütter, mit Lücken besät, auffallend stark vascularisirt, vermehrte Gliakerne und entsprechend den Zellenlücken Bindegewebswucherung.

Sommer (Erkr. d. Ammonshorns als ätiol. Moment d. Epilepsie. Arch. f. Psych. X. 1880) beschreibt in seiner Arbeit die Veränderungen folgendermaassen: Die Pyramidenzellen fehlen oft anf betrïchtlichen Strecken; auf den Rändern der Defecte fand er selbe verkleinert, jedoch schreibt er dies nur dem Plasmaschwunde zu, da er die Kerne in unveränderter Grösse antraf; ausserdem sind die periganglionären Lücken an diesen Zellen kleiner als normal. Nach seiner Beschreibung sind in einem späteren Stadium die Ecken der Pyramidenzellen der Basis zu eingezogen, die Zelle ist wie abgerundet; später lugt der Kern von der geschrumpften Zelle hervor, - noch später steht der Kern allein, höchstens liegt ihm hie und da ein krümliches Protoplasmahäufchen an. Ebenfalls Sommer beschreibt in zwei anderen Fällen Lücken an Stelle einiger Pyramidenzellen, immer vis-àvis des Subiculum Cornu Ammonis, in denen 1-4 ovoide Kerne sitzen (wahrscheinlich Gliakerne. Autor), ausserdem Fettropfen und einen amorphen gekörnten Detritus. Die stehengebliebenen Zellen fand er auch grössten- 
theils verändert, die Contouren gekerbt, im Zellleib zahlreiche gelbe Kügelchen.

Bouchard fand an den Stellen, wo die Pyramidenzellen untergegangen sind, das $Z$ wischengewebe erkrankt; von der Norm abweichend, ist dasselbe eine feingekörnte, gleichmässige Masse geworden, mit zahlreichen Fasern, Blutgefässen und abgerundeten Kernen (wahrscheinlich Gliakerne. Autor). An jenen Stellen der Pyramidenschichte, welche in der Nachbarschaft der destruirten Partieen liegen, sind die Kerne der Pyramidenzellen vergrössert, sind der Zellenbasis zu gerückt, scharf conturirt und fein granulirt. Später geht das Zellplasma verloren, überlässt seinen Platz dem wachsenden Kerne, welcher schliesslich die ganze Zelle eimnimmt. Später erkranken auch die Kerne; sie werden kleiner, ihre Zahl nimmt ab.

Coulboult (Des lésions de la corne d'Ammon dans l'Epilepsie. Paris 1881) approbirt in seiner Arbeit den Befund vou Bouchard.

Collins (A contribution to the pathology of epilepsy. Brain. II. III. 366. Seite) beschreibt ebenfalls degenerative Erkrankungen in der Pyramidenzellenschichte, sowie auch stellenweise gänzlichen Schwund der Zellen.

Nerander (Studien über die Veränderungen in den Ammonshörnern und naheliegenden Theilen bei der Epilepsie. Jahresschr. d. Univ. zu Lund. XXX) beschreibt circumscripte Gliawucherungen in den Ammonshörnern der Epileptiker; die Nervenzellen sind stellenweise verschwunden; das $Z$ wischengewebe ist locker geworden, ist vielfach durch Lücken unterbrochen; die Adventitia der Gefässe ist verdickt; ausserdem sind häufig Unregelmässigkeiten in der Pyramidenzellenschichte und Heterotopieen in der Kernzellenschichte der Fascia dentata (Pallisadenschichte) zu finden.

Die bis jetzt angeführten Forschungen stammen alle noch von der Zeit vor den neuesten technisehen Errungenschaften der Histologia; meistens benützte man durch Carmin gefärbte Präparate.

Seitdem NissI sein Tinetionsverfahren angab, we lches eine, früher gar nicht geahnte Einsicht in den inneren Bau der Nervenzellen gestattet, sind die früher angegebenen mikroskopisehen Befunde gar nicht nachgeprüft worden; wo doch dieses neuere Verfahren am ebesten einen Fortschritt in unseren path. anatomischen Kenntnissen über Epilepsie verspricht. Ich fand in der mir zu Gebote stehenden Fachliteratur einzig nur von Bratz ein Referat von seinen Forschungen (Vortrag, gehalten in der Berliner Gesellschaft f. Psychiatrie u. Nervenkr. am 13. Decemb. 1897) die er an 50 Fällen von Epilepsie durchfülırte. Leider steht mir hiervon nur ein kurzes Referat zu Gebote, von dem ich er- 
sehe, dass die Untersuchungen grösstentheils nur makroskopisch angestellt wurden. Von seinen mikroskopischen Befunden wissen wir nur so viel, dass er häufig Veränderungen dort antraf, wo die makroskopischen Veränderungen normale waren, andererseits fand er normales mikroskopisches Verhalten bei makroskopisch sichtbaren Erkrankungen. Die Destruction findet er meistens in der Atrophie der Pyramidenzellen, deren Stelle von vermehrtem Gliagewebe eingenommen wird.

Seit dem Jahre 1895 untersuchte ich 4 Epilepsiefälle mikroskopisch, und bei allen diesen fand ich mehr weniger Erkrankung der Ammons hörner. Heine Untersuchungen stellte ich an Präparaten an, die nach Nissl's Methode gefärbt wurden. Die Gehirntheile fixirte ich die ersteren in Alkohol, die späteren dann in 10 proc. Formalinlösung; darnach wurden dieselben mit Celloidin imprägnirt. Anfangs färbte ich mit Nissl's B. patent Methylenblau, später mit Thionin. Die Schnitte erhitzte ich in der Farbenlösung bis zum Erscheinen der ersten Blasen, nachträglich entfernte ich aus den Schnitten die überschüssige Farbe in anilinölhaltigem Alkohol und vertrieb nachher das Anilinöl durch Cajeputöl und schliesslich durch Benzin. Die so gefärbten Schnitte wurden in Canadabalsam eingeschlossen, woraus ich durch nachträgliches Erhitzen jede Spur von Xylol vertrieb. Das übrige Untersuchungsmaterial bildeten ausserdem mit Carmin, nach Weigert's Markfürbung und nach Weigert's Gliafärbung hergestellte mikroskopische Präparate.

Für das Studium der Veränderungen fand ich die Nissl'sche Tinctionsmethode am geeignetsten, da die Zellenerkrankung in den Bildern zweifelsohne das Wichtigste ist. Die Destruction der Ganglienzellen werde ich in den vier Fällen ganz detaillirt abbandeln; hier gleich will ich erwähnen, dass die Carminpräparate in mehreren Fällen Vermehrung der Capillaren, starke Injection und eine Verdichtung des intercellularen Gewebes zeigten mit dunkler gefärbtem Glianetze und mit Vermehrung der Gliakerne. In einem Falle fand ich an der Ventrikeloberfläche, insbesondere um die Blutgefässe herum viele Amyloidkörper. (Fig. 1.) Weigert's Markfärbung giebt keine besonders instructive Bilder und eignet sich höchstens zum makroskopischen Vergleich der beiderseitigen Ammonshörnerdurehschnitte; daraus ersehen wir, dass die Atrophie der Ammonshörner sich hauptsächlich auf die zelligen Elemente beschränkt; in Folge dessen ist die Marksehichte, welche dem Alveolus entsprechend verläuft - scheinbar nur durch eine schmale Spalte von der Lamina medullaris involuta getrennt; diese Spalte wird von der atrophischen, stellenweise verschwundenen Pyramidenzellenschichte eingenommen. Hit Weigert's Markfärbung war in 
mehreren Fällen eine ausgesprochene Ependymitis zu erkennen; (vergrösserte Ependymzellen, die in mehrere Reihen gedrängt ibre cylindrische Form verloren haben, ausserdem ein amorpher Detritus, stellenweise gänzlicher Schwund der Ependymzellen) nebst einer bedeutenden Hypertrophie der tangentialen Gliaschichte. (Fig. 2). In einem Falle wies ich in dem sklerotischen Ammonshorn durch Gliafärbung eine Vermehrung der Astrocyten auf mit einem, dem Normalen viel dichteren Gliageflechte (insbesondere in der Bucht der Fascia dentata) und Vermehrung der dickeren Gliafasern.

Während die bisher beschriebenen Erkrankungen mit den makroskopisch erkennbaren Veränderungen des Ammonshorns Schritt hielten, weist die Nissl'sche Methode in einem jedem Falle Zellerkrankung anf, selbst in jenen Fällen, wo bei der Obduction normale Ammonshörner vorgefunden wurden.

In den folgenden Capiteln werde ich eine genaue Schilderung der vier untersuchten Epilepsiefulle liefern. Ich hebe hervor, dass ich in jedem Falle das ganze centrale Nervensystem histologisch untersuchte, und wenn doch nur von den Ammonshörnern die Rede sein wird, so liegt der Grund darin, dass bei der in jedem Falle beständigen Erkrankung dieses Organes die Alteration anderer Stellen sehr variirt, trotzdem aber war die Art der Erkrankung bei jeder Localisation identisch mit derjenigen der Ammonshörner. Im Vergleiche mit diesen, im Typus stets wiederkehrenden, bezüglich der Localisation gänzlich heterogenen pathologischen Veränderungen fanden sich in allen meinen Fällen die Ammonshörner stets erkrankt, und zwar meist in stärkerem Grade, als die Erkrankungen anderer regelloser Localisation.

Aus diesem Umstand ersehen wir, dass die Erkrankung der Ammonshörner das Wesentliche der Sache ist, das übrige ist nur accidentell, es erscheint sogar als ein path.-anatomischer Beweis für die pathogenetische Wichtigkeit der Ammonshornerkrankung bei Epilepsie.

Ich werde in dem Folgenden eine ganz genaue Beschreibung der Ammonshornveränderungen geben, bei den Erkrankungen der anderen Partieen aber beschränke ich mich nur auf die Wiedergabe der makroskopischen Verhältnisse.

\section{Beobachtung.}

H. K., 26 Jahre alter Schuster. Seit Kindheit litt er an häufig wiederkehrenden epileptischen Anfällen; in letzter Zeit kamen dieselben täglich öfters; auch waren die Symptome einer geistigen Decadenz zu beobachten. Er starb im St. Johannes-Spitale zu Ofen am 28. Mai 1897 während eines Status epilepticus. Für die gütige Ueberlieferung des Untersuchungsmaterials 
will ich gleich hier meinen Dank an den hochverehrten Herrn Prof. Genersich aussprechen.

Bei der Section ergab sich neben einer frühzeitigen Ossification der Schädelknochen und der Verdiekung der Meningen ein positiver Befund an den Seitenventrikeln; dieselben sind erweitert, ihr Ependym ranh, die Hinterhörner sind verlängert. Die Ammonshörner weisen keine makroskopische Veränderung auf, höchstens dass sich das rechte etwas härter anfühlt.

Mikroskopischer Befund.

Rechtes Ammonshorn: Vis-à-vis des Subiculum fehlt die Schichte der grossen Pyramidenzellen in der Länge des Drittels des Alveusbogens. In diesem beschriebenen Segmente, welches dem Defecte entspricht, ist das intercelluläre Gliagewebe verdichtet und färbt sich intensiv. Die Schichtung. zwischen der Ventrikeloberfläche des Alveus und der Pallisadenschichte der ovoiden Zellen ist nicht aufzufinden (Fig. 3). Die Schichte der Pyramidenzellen ist im Allgemeinen, insbesondere aber in der Nähe des Randes jener unterbrochenen Stellen, schmäler und zellenarmer als de norma. Innerhalb der Fascia dentata ist in der Bucht der Pallisadenschichte die Zahl der polygonalen Zellen vermindert. Das ganze Ammonshorn ist besonders stark vascularisirt.

Die Veränderung der Zellenstructur ist am anffälligsten in der Schichte der Pyramidenzellen, dann folgen die polygonalen Zellen in der Bucht der Fascia dentata; - die geringste Veränderung treffen wir in den Zellen der Pallisadenschichte an. Diese Reihenfolge werde ich auch einhalten in der Beschreibung der Structurveränderungen.

Pyramidenzellenschichte: Die Pyramidenzellenschichte des Gyrus hippocampi beginnt entsprechend der Fissura hippocampi zellenarmer zu werden; in der Ammonswindung finden wir ihre Zellen bereits meistens in verschiedenem Grade verändert. Bei der geringsten Stufe der Destruction (Fig. 4) finden wir die Zellkerne vergrössert; der Punktkranz um den Kern herum tritt scharf hervor; der Kerncontour ist scharf. Der stychochrome Bau der Zelle ist erhalten, doch sind die Chromatinkörnchen kleiner, färben sich oft weniger und zerfallen in ganz kleine Körnchen. An anderen Zellen ist wieder die stychochrome Structur mehr erhalten, doch ist der Kerncontour verwischt und der Kern färbt sich diffus dunkler als das Zellenparaplasma.

Eine andere Art der Zellenveränderung ist durch die Kernschrumpfung charakterisirt. Entsprechend der Runzelung der Kernmembran sieht man am Kerne unregelmässigg verlaufende dunkle Striche; ausserdem zeigt der Kerncontour einseitige Einkerbungen oder hat gar eine Biscuitform angenommen (Fig. 5); das Zellenchromatin hat sich theils in intensiv färbbare Sohollen zusammengeballt, theils ist sie in grobe Körner zerfallen. In anderen Zellen bildet wieder das Chromatin noch grössere dunkle Schollen, die einen bedentenden Theil der Zelle einnehmen (Fig. 6), hingegen ist hier der Kern wieder grösser und rund, seine Faitungen sind grösstentheils verschwunden; doch erscheint in ihrem Inneren eine ungefärbt bleibende Vacuole, als wie wenn 
sie durch Flüssigkeitsansammlung gebildet, das Kernplasma auseinandergeschoben und den bereits geschrumpften Kern wieder rund gemacht hätte.

Es scheint, als ob die jetzt beschrjebenen Zellen einen Uebergang zu jenen Zellen darstellen würden, deren Kerne so zu sagen verschwunden sind (Fig. 7), nur ein sich weniger färbender ovaler Fleck in der Zelle zeigt ihren Platzan; das Kernkörperchen ist entweder gedunsen und fein punktirt oder aber ist es um vieles kleiner als normal. Den Körper einer solchen Zelle bilden so zu sagen nur einige Vacuolen, welche hier und da geplatzt sind und mit dem periganglionären Raume communiciren. Von stychochromem Baue haben diese Zellen gar keine Spur; das Chromatin ist in feine, stellenweise dichter stehende Körnchen zerfallen.

Ein ganz anderer Typus der Zellenerkrankung $(8,9,10,11)$ wird hauptsächlich charakterisirt durch einen feinkörnigen Zerfall oder aber durch eine homogene Auflösung des Zellenchromatins; weiterhin erscheinen bei diesem Typus am Rande oder im Inneren der Zelle Gliakerne, die von einem freien Hofe (wahrscheinlich der ungefärbt gebliebene Leib der Gliazelle) umgeben sind und hierdurch erscheinen an den Zellengrenzen muldenförmige Vertiefungen oder vacuolenförmige Lücken im Zellenleibe. Oft sitzen in so einer Mulde oder Vacuole mehrere Gliakerne; andere Male bilden sich in einer Zelle auch mehrere solche Vacuolen $(9,11)$. Bei einigen wenigen Zellen finden wir neben der beschriebenen Veränderung eine Multiplicität des Kerns; manche haben zwei oder drei Kerne mit je einem Kernkörperchen; ausserdem finden wir in dem fein gekörnten oder homogenen Zelljeibe einige helle, scharf umschriebene, runde Flecke, die als ihres Kernkörperchens verlustig gewordene Kerne erscheinen, oder aber es sind neugebildete Zellkerne, welche noch keinen Nucleolen erhalten haben. Bei einer vorgeschritteneren Phase dieser beschriebenen Frkrankung wimmelt es in der Zelle und um die Zelle herum von Gliakernen; von dem Plastra der Zelle sind nur melr Fetzchen übrig geblieben; anderswo sehen wir von $\$$ bis 10 beisammenstehenden Gliakernen gebildetes Nest, das wir mit Recht als die Untergangsstätte eirier bereits verschwundenen Zelle betrachten können. Es ist auffallend, dass dieser beschriebene gliakernige Destructionsprocess so selten den Zellkern angreift; an den Präparaten sehen wir, dass, wenn auch dies der Fall ist, der Process zuerst den Zellleib befallen hat und nur im weiteren Fortschreiten auch auf den Kern übergegangen ist.

Ich glaube zweifellos behaupten zu können, dass die beschriebene Erkrankung destructiver Natur sei; dabei ist die Frage gleichgültig, ob die Gliakerne primär die Zelle annagen, oder ob die Vacuolenbildung der Zelle das Primäre und das Hineinwandern der Gliazellen das Secundäre sei; - die mikroskopischen Bilder sprechen eher für die erstgenannte Annahme, Da mein Zweck nur za beschreiben ist und ich mich nicht in weitere Erklärungen einlassen will, werde ich zur besseren Jllustration dieser Zellenerkrankung diese Gliakerne als Ganglioklasten, die Zollenveränderung selbst als ganglioKlastische Destruction bezeichnen. Selbstredend stelle ich diese Benennungen 
nur zum $Z$ weeke der besseren Illustration auf und nicht als das Excerpt einer Erklärung.

Jene Zellen der Pyramidenzellenschichte, welche am Rande der gänzlich destruirten Zellenpartie liegen (12), sowie auch jene übrig gebliebenen Zellen, die sich in den leeren Inseln vereinzelt vorfinden (13), weisen ausnahmslos jene Erkrankung auf, die als Sklerose bezeichnet wird. Das Chromatin der randständigen Zellen ist zu groben. Schollen zusammengebacken, dabei ist der Zellenrand hie und da defect, und das Zellenparaplasma hat sich in toto, oder wenigstens an den Polen, diffus dunkler gefärbt. Die vereinzelten Zellen der fehlenden Schichtenpartie stehen bereits auf einer höheren Stufe der Sklerose: sie färben sich diffus dunkler, und nur das Centrum der Zelle ist etwas heller; hier können wir manchmal noch den Nucleolus erkennen. Die so besehriebenen skierotischen Zellen sind auffallend kleiner, als die normalen Pyramidenzellen, ihre Dendritfortsätze färben sich dunkel und zerbröckeln an vielen Stellen. Die höchste Stufe der Sklerose finden wir in einigen dunkel gefärbten, gar keine Zellform mehr aufweisenden Schollen.

In der Bucht der Pallisadenschichte ist die Zahl der polygonalen Zellen vermindert, mit Ausnahme einiger weniger Zellen, die einen normalen stychochromen Bau aufweisen, stehen die übrigen auf verschiedener Stufe der Sklerose; sie sind kleiner wie in der Norm, ihre Kerne färben sich dunkel, ohne jedwede Körnung; ihre Nucleolen sind grösser und kaum dunkler als die Grundmasse des Kerns und fallen nur durch ihre intensiver gefärbten Contouren auf (14). Bei einer anderen Serie der polygonalen Zellen verschwindet das Zellkörperchen, der Kern rückt an den Zellenrand und erscheint, als wenn er eine mit homogener Masse erfüllte Aushöhlung der Zelle wäre (15).

Von den ovoiden Zellen der Pallisadenschichte ist nur Weniges zu bemerken; stellenweise liegen die Zellen nicht ganz dicht noben einander; hie und da sind freiliegende Kerne zu finden (16):

Ausser den beschriebenen Ganglienzellenerkrankungen finden wir, dass die Gliazellen im Allgemeinen, insbesondere jedoch in der Pyramidenzellenschichte, vermehrt sind; die Gefässe und Capillaren sind von normalem Aussehen und normaler Zahl; die Ependymzellen stehen stellenweise in mehreren Schichten und hie und da finden wir an ihrer Stelle Zellendetritus.

Das Verhalten des linken Ammonshornes stimmt mit dem der rechten Seite vollkommen überein, nur sind die degenerirten Zellen der Pyramidenzellenschichte geringer an Zahl; meistens ist der Ganglioklastentypus vertreten (17); ausserdem besteht hier nirgends ein vollkommener Defect der Pyramidenzellenschichte.

Fassen wir nun den Befund dieses ersten Falles zusammen. Bei der Section fanden wir die Seitenventrikel erweitert, ihr Ependymüberzug fühlte sich rauh an; die beiden Ammonshörner wiesen makroskopisch nichts Patbologisches auf, höchstens dass sich das rechte härter anfühlte. Die mikroskopische Untersuchung ergab in beiden Ammonshörnern Erkrankungen, welche in dem sclerotisch sich anfühlenden 
rechtseitigen Horne in Anbetracht der Zahl der degenerirten Zellen und der Stufe der Degeneration bereits mehr vorgeschritten ist. Der Hauptsitz der Ganglienzellendestruction ist die Pyramidenzellenschichte; geringer ist die Destruction in der Bucht der Pallisadenschichte; ihre polygonalen Zellen sind in Folge ihres anatomischen Verhaltens gleichwerthig den Pyramidenzellen. Diese sind durch den Hilus quasi himeingefallen in die Bucht der Pallisadenschichte, und da ihre Neuraxone und Dendritfortsätze sich in jeder Richtung hin frei entwickeln konnten, haben sie nicht nur ihre schichtenweise Anordnung, sondern auch ihre Pyramidenform verloren. Diese Auffassung beweist in Anbetracht der localen Verhältnisse der Nervenzellen-Entwickelung, dass dieselben Zellen, welche, in einer Schichte dicht nebeneinander gereiht, Pyramidenform haben, frei gewachsen polygonale Form annehmen. Das ist ja dasselbe Verhältniss, wie das der Bäume im Walde; stehen sie dicht nebeneinander, so wachsen sie hoch, ihre Krone wird schmal; stehen sie weit auseinander, so bleiben sie niedriger, entwickeln sich jedoch in die Breite. Während die zu einander verwandten Pyramiden- und polygonalen Zellen hochgradig erkrankt gefunden werden, weisen die Zellen der Pallisadenschichte kaum eine nennenswerthe Veränderung auf.

Die Degeneration der Pyramiden- und polygonalen Zellen können wir in drei Hauptoruppen zusammenfassen. Bei der ersten ist die Erkrankung des Zellkerns das Vorherrschende; dieser ist entweder vergrössert oder geschrumpft; später treten darin Vacuolen auf, wodurch sich der Kern wieder aufbläht; dann wird er defect, verliert bei manchen Zellen seine Contour, und nur der vergrösserte, gekörnt gewordene Nucleolus zeigt seinen Platz an. Der Grad der destructiven Veränderung des Zellplasmas ist proportionirt der Kernerkrankung; an Stelle des normalen stychochromen Baues finden wir einen körnigen Zerfall des Chromatins oder finden dieses in grössere Schollen zusammengeklebt; das Paraplasma ist in einem Segment der Zelle oder in toto diffus, jedoch verschieden dunkel gefärbt.

Die zweite Gruppe ist die ganglioklaste Form der Erkrankung; hierher können wir auch jene Zellenformen rechnen, bei denen mehrere Zellkerne zu finden sind.

Die dritte Gruppe bilden jene sclerotischen Zellen, welche in der Nähe der Defecte der Pyramidenzellenschichte, in geringer Zahl auch in der Bucht der Pallisadenschichte zu finden sind; bei diesen färbt sich die Zelle dunkel, an Stelle des stychochromen Baues finden wir grosse Chromatinschollen oder diffuse dunkle Färbung: der Kern ist an den Rand der Zelle gedrückt oder ist gar nicht mehr aufzufinden, und nur das Kernkörperchen weist auf seinen Platz hin. Diese dritte scle- 
rotische Gruppe ist wahrscheinlich nur ein vorgeschritteneres Stadium der Veränderungen der ersten Gruppe.

In den Zellen der Pallisadenschichte finden wir kaum eine Veränderung; höchtens fällt die Zellenarmuth der ganzen Schichte auf.

Ausser der Erkrankung der Ganglienzellen können wir eine Vermehrung und Degeneration der Ependymzellen constatiren; das Gliagewebe ist hypertrophisch, die Gefässe an Zahl vermehrt: beides insbesondere am Orte des Pyramidenzellendefectes.

\section{Beobachtung.}

E. J., 29 Jahre alter Componist, gestorben am 29. August 1897 in einem Status epilepticus. Vater und zwei Brüder waren ebenfalls von Epilepsie befallen. Seine Krankheit bestand seit 10 Jahren, mit täglich 5-6 Anfällen. In letzterer Zeit ist die Zahl der Anfälle sehr angewachsen. 3 Tage vor dem Tode zeigte sich an ihm eine Geistesverwirrung, in Folge deren er auf die psychiatrische Klinik transferirt wurde. Von dieser Zeit an erlangte er die Besinnung gar nicht wieder; unter Delirien und clonischen Krämpfen trat der Exitus letalis ein.

Sectionsbefund: Das Schädelgewölbe ist verdickt; die Meningen sind stark injicirt, leicht abziehbar, reissen leioht ein. Der linke Seitenventrikel ist erweitert, sein Hinterhorn verlängert; das Ependym ist glatt, sehr stark injic̈irt. Linker Fornix ist nur halb so dick als der rechte; auch das Ammonshorn ist um die Hälfte schmaler, fühlt sich beinahe knorpelhart an. Der rechte Seitenventrikel ist von normaler Dimension, sein Ependymüberzug ist gekörnt, rauh anzufühlen, die Contouren der Gefässe treten nicht so scharf hervor als linkerseits; das rechte Ammonshorn ist nicht so stark gewölbt als das linke; es ist doppelt so breit, ganz weich, in der Mitte der ganzen Länge entlang eingesunken. Die Grössenverhältnisse der beiden Ammonshörner ersehen wir von der Figur 18; dieselbe ist von oben gesehen und in einem der Längsachse verticalen Durchschnitte gezeichnet. Beide Durchschnitte wurden geführt an den Halbirungspunkten der Ammonshörner (a. b.).

\section{Mikroskopischer Befund.}

Rechtes Ammonshorn: Die Pyramidenzellenschichte ist stellenweise zellarm, doch finden sich darin keine ganz leere Stellen. Die polygonalen Zellen der Fascia dentata, sowie anch die ovoiden Zellen der Pallisadenschichte haben einen normalen Zellenreichthum. Das ganze Ammonshorn ist reich an Gefässen, insbesondere auffallend sind die radiär verlaufenden Gefässe der Pyramidenzellenschichte; auch die Bucht der polygonalen Zellen ist besonders reich an Gefässen. Das Gefässlumen ist stark erweitert, ist mit Blutkörperchenrollen getüllt. Den Gefässen entlang finden wir vermehrte Astrocytenkerne.

In der Pyramidenzellenschichte finden wir meistentheils normalen stychochromen Bau, nur vereinzelt, und zwar an der oberflächlichen Seite der 
Schichte, kommen auch an der ganglioklastischen Veränderung erkrankte Zellen vor; unter diesen haben einzelne bloss don Zellkern beibehalten.

Vorgeschrittener ist die Erkrankung der polygonalen Zellen. Ihre Zahl ist de norma kaum vermindert, jedoch finden wir kaum welche normal gebante Zellen. Die hier vorherrschende Erkrankung können wir hydropisches Anschwellen nennen. In grosser Zahl treffen wir viel grössere Zellen de norma an, die noch in verschiedenem. Grade ihre stychochrome Structur bewahrten; doch stechen die Chromatinschollen vom Grunde nicht so scharf hervor; die ganze Zelle hat sich verschwommen gefärbt; es hat den Anschein, als wie wenn das Chromatin sich langsam in dem Paraplasma auflösen würde. Die Kerne dieser Zellen haben keine scharfe Contouren; der Kern manoher Zelle ist wie gedunsen; sein Kernkörperchen ist blasser, mit etwas dunklerer Contour (Fig. 20). Neben diesen hydropisch angeschwollenen Zellen finden wir auch einzelne kleinere, welche sich diffus dunkel färben und nur die helle Scheibe ihrer Kerne hebt sich hervor; der gedunsene Nucleolus dieser Zellen ähnelt sehr dem Kernkörperchen der früher beschriebenen Formen und aus diesem Umstande ersehen wir, dass es sich eigentlich um eine vorgeschrittene Stufe der vorerwähnten Degeneration handelt. Wir müssen annehmen, dass in Folge der serösen Durchfeuchtung das Zellenplasma vollkommen homogen -wird; später fällt die Zelle in Folge Säfteverlust zusammẹn und ersoheint in einer dunkleren Farbe. Das Endstadium dieser Degeneration bilden wahrscheinlich jene stellenweise vorkommenden, dunkel gefärbten, kleinen Zellen, die absolut keine Structur mehr aufweisen, deren Dendritfortsätze sjch ebenfalls dunkel färben und vielfach zerbröckeln. Diese letztgenannten Zellen sind entschieden sclerotisch.

Ausser dieser beschriebenen Degeneration finden wir in grosser Zahl meistens den neugebildeten Gefässen entlang - auf verschiedener Stufe der ganglioklastischen Erkrankung sich befindende Zellenformen.

Die ovoiden Zellen der Pallisadenschichte weisen ein ganz normales histologisches Verhalten auf.

Linkes Ammonshorn: Schon bei der Section ist uns dieses Horn in Folge seiner knorpelharten Consistenz aufgefallen. Nach der üblichen Fixation in 10 proc. Formalinlösung, Entwässerung in Alkohol und Celloidinimprägnatiou hat die Consistenz in solchem Maasse zugenommen, dass die Herstellung feiner Schnitte besondere Schwierigkeiten hatte; so mussten wir uns bei der Untersuchung an Stelle vollkommener Schnitte, mit einzelnen kleinen, jedoch hinlänglich dünnen Fetzchen zu Frieden geben, und aus diesen konnten wir erst das histologische Gesammtbild des Ammonshorns construiren. Schon bei schwacher Vergrösserung fällt uns folgendes Pathologische auf (Fig. 21). Die Ganglienzellen der Pyramidenschichte sind ganze Serien hindurch vollkommen verschwunden; die Stelle der fehlenden Schichte erfüllt ein dicht punktirter Streifen, bestehend aus besonders stark vermehrten Astrocytenkernen. Die polygonalen Zellen liegen vereinzelt zerstreut; am Kopfende des Ammonshornes fehlen dieselben in einzelnen Inseln gänzlich. Die Pallisadenschichte der ovoiden Zellen ist zwar genügend zellenreich, ist jedoch stark durchbro- 
chen von injicirten Blutgefässen, deren Wände verdjckt, die Endothelkerne vermehrt sind. Auffallend ist die grosse Zahl der nengebildeten Gefässe; an vielen Stellen der Bifurcation finden sich miliäre Aneurysmen. Die Astrocyten sind ebenfalls vermehrt, insbesondere in den Defectinseln der Pyramidenzellenschichte.

Bei starker Vergrösserung fällt in der Pyramidenzellenschichte die grosse Zahl der sklerotischen Zellen auf: es sind nur die geschrumpiten grobscholligen Kerne der Zellen übrig geblieben; das Kernkörperchen ist oft gar nicht aufzufinden; der Zellenrand ist zerbröckelt, von dem Plasma ist nur um die Dendritenwurzeln herum etwas amorpher Detritus geblieben; die Dendriten selbst haben sich dunkler gefärbt und sind an vielen Stellen zerbröckelt (Fig. 22). Bei der überwiegenden Mehrzahl der sklerotischen Zellen finden wir vereinzelt auch solche von normaler Structur; bei diesen ist auffallend ihr relativ grosser Pigmentreichthum. Hie und da finden wir unter den Pyramidenzellen, insbesondere den Gefässen entlang, auch vereinzelte ganglioklastische Formen.

Die polygonalen Zellen der Fascia dentata haben an Zahl sehr abgenom.. men: ausser einigen von normalem stychochromen Ban, ist vorherrschend der sklerotische Typus (Fig. 23). Von diesen sind meist nur die dunkel gefärbten, an den Rändern mit Punktkreis versehenen Kerne übrig geblieben; von dem Zellleib ist nur an der Dendritwarzel etwas geblieben, an anderen Stellen finden wir stark gefärbte Trümmer als Residuen einer verschwundenen Zelle.

Die ovoiden Zellen sind meistentheils: gesund, nur stellenweise liegen sie schütter; an solchen Stellen sind die Zellenkerne gedunsen oder aber geschrumpft, an der Oberfläche der Kerne sehen wir Falten. Auch hat an jenen Stellen das Zellen plasma den stychochromen Bau verloren, und ist fein gekörnt worden; von einzelnen Zellen ist nur der Kern geblieben oder aber weist je ein anhaftendes körniges Fetzchen auf den verschwundenen Zellleib hin. (Fig. 24.)

Wenn wir das Ergebniss unserer Untersuchung in diesem Falle zusammenfassen, ist in dem rechten Ammonshorne, welches schon bei der Obduction als erweicht imponirte, am meisten aufgefallen das hydropische Anschwellen der polygonalen Zellen; bereits seltener waren die geschrumpiten und dunkel sich färbenden Exemplare, dagegen war der ganglioklastische Typus in genügender Anzahl vertreten. Die Pyramidenzellen waren grösstentheils gesund, ebenso auch die ovoiden Zellen der Pallisadenschichte. Die Blutgefässe fanden wir vermehrt and erweitert; die Zahl der Astrocyten stark angewachsen.

Bei dem linksseitigen, bei der Obduction knorpelhart sich anfühlenden, sklerotischen Ammonshorn ist uns die beträchtliche Verminderung der prolygonalen und Pyramidenzellen aufgefallen; stellenweise waren ganz leere Inseln zu finden; die Astrocyten fanden wir stark 
vermehrt, ebenso die Blutgefässe. Der vorherrschende Degenerations: typus der polygonalen und Pyramidenzellen ist die Sklerose; am längsten widerstehen derselben die Kerne.

\section{Beobachtumo.}

F. Gy., 16 Jahre alter Tischlerlehrling. Die Anamnese war nur lückenhaft zu eruiren; nur so viel ist sicher, dass er seit frühester Kindheit an häufig wiederkehrenden epileptisehen Anfällen litt. Am 17. Mai 1897 ist er mit den Symptomen hochgradiger psychischer Incohärenz im St. Rochus Spitale zu Budapest aufgenommen worden, von wo er wegen seiner Unruhe schon am nächstfolgenden Tage auf die psychiatrische Klinik überführt wurde. Eine nähere Untersuchung ergab hier, dass der Kranke schon seit zwei Wochen keinen Stuhl hatte; Tags darauf traten ausgesprochene Ileussymptome auf; unter peritonealen Reizerscheinungen und Collaps trat am folgenden Tage der Exitus ein, ohne dass wir an ihm epileptischen Anfall gesehen hätten.

Die Section ergab Geschwüre im Dünndarm, unter diesen war eines perforirend: die Gedärme waren verklebt und mit grünlichem, putrid riechendem Eiter überzogen.

Die Meningen waren hyperämisch, injicirt; die Leptomeninx von normaler Dicke, durchscheinend; dieselbe war von der Gehirnrinde schwer abzulösen. Die Gehirnrinde war blutarm, das Mark lyyperämisch; das Ependym der Seitenventrikel erweicht, die Hinterhörner verlängert; beide Ammonshörner, doch hauptsächlich das linke, waren schmal, fühlten sich härter an. In den grossen Gehirnganglien, im Kleinhirn und in der Medulla war nichts Abnormes.

Diagnose: Hyperaemia meningum; Ependymitis chronica; Sclerosis cornu Ammonis lat. utr.; Ulcera ad intest. jejun.; Perforatio magnitud. fere $2 \mathrm{~cm}$.; Peritonitis ichorosa.

\section{Mikroskopischer Befund.}

Rechtes Ammonshorn. Bei schwacher Vergrösserung fallen nur die recht zahlreichen, stark injicirten Gefässe auf; die Pyramidenzellenschichte der Fascia dentata ist stellenweise zellenarm; diese Armuth an Zellen ist auch in einzelnen Inseln der Pyramidenschichte des Gyrus hippocampi anzutreffen. Die Astrocyten sind im Allgemeinen vermehrt.

Die Structur der Pyramidenzellen erweist sich grösstentheils als normal, nur stellenweise zeigt sich, entsprechend dem Verlaufe einzelner Gefässe, die ganglioklastische Form der Erkranlung; und zwar zeigen sich bei diesen die Aushöhlungen und Höhlenbildungen meistens an der Pyramidenbasis. Viel mehr degenerirte Zellenformen fanden sich in den erwähnten Inseln der Pyramidenschichte im Gyrus hippocampi; daselbst traf sich nebst dem ganglioklasten Typus auch einfache Zellenschrumpfung, resp. Sklerose in genügender Anzahl an.

Grössere Dimensionen zeigt die pathologische Veränderung bei den polygonalen Zellengruppen der Fascia dentata. Hauptsächlich finden wir die gan- 
glioklastische Form vertreten; doch sind die Astrocyten, welche die Zellen angreifen, weniger an Zahl, als wir dies im ersten Fall gesehen haben: oft finden wir nur einen Astrocytenkern, welcher in der Vacuole des Zellkernes, neben dem Nucleolus sitzt. Eine andere Art der Zellenerkrankung besteht darin (Fig. 26), dass das Chromatin in kleineren, bald grösseren, eckigen, stark lichtbrechenden, an Glastrümmer erinnernden Körnern erscheint; wenn diese Körner grösser sind, so sehen wir beim Drehen der Mikrometerschraube in vorschiedener Einstellung einmal den Kern der Schollen heller, die Umsärumung dunklèr, bald wieder erscheint der dunkle Kern mit einer hellen, glitzernden Umsäumung. Je grösser diese Glastrümer ähnlichen Chromatinschollen sind, desto mehr bewahren dieselben in ihrer Localisation die ursprüngliche tigroide Anordnung. Das Paraplasma dieser Zellen hat sich bei einigen (besonders bei den feiner Gekörnten) diffuse heller gefärbt, andere wieder blieben ganz untingirt. Die Kerne der beschriebenen Zellen sind reich gekörnt, nur um den Nucleus herum lassen sie einen leeren Hof frei, in diesem sitzt das glitzernde, dem stark lichtbrechenden Chromatin ähnliche Kernkörperchen: Andere Zellen weisen einen feinlörnigen Zerfall auf; die Zellenconturen sind beinahe ganz verschwunden; von den Zellenbestandtheilen ist nur der Nucleolus unter dem gekörnten Zellendetritus zu erkennen. Bei den relativ gesunden polygonalen Zellen finden wir grösstentheils einen auffallenden Pigmentreichthum.

Am auffälligsten ist in diesem Ammonshorne die Erkrankung der ovoiden Zellen. Eine Verminderung derselben konnte ich nicht constatiren. Eine deutliche degenerative Veränderung dieser Schichte finden wir in einzelnen an Gliakernen reicheren Flecken derselben. Der Zellleib der degenerirten ovoiden, Zellen ist fein punktirt, ohne jede Spur von stychochromem Bau; ihre Kerne färben sich diffus dunkler, sind zu Bohnen- oder Biscuitform deformirt oder eckig geschrumpft. Der homogen gefärbte Zellkern hat ein, den Blutkörperchen ähnliches Lichtbrechungsvermögen; bei einer gewissen Einstellung ist ihre Mitte dunkler, bei einer anderen wieder der Rand. Fin Nucleolus ist in den meisten solchen Zellkernen gar nicht aufzufinden (Fig. 28). Im Allgemeinen ist die Cohärenz der ganzen Pallisadenschichte an diesen erkrankten Stellen gelockert; dies erkennen wir ans den Rissen, welche bei der ganzen Schnittserie immer auf dieser Stelle auftreten, und die Richtung der Schichte verfolgen. Es sei noch bemerkt, dass an diesen erkrankten Flecken der Pallisadenschichte ausser der Vermehrung der Astracyten auch eine besonders reiche Gefässneubildung in radiärer Richtung auffällt.

Linkes Ammonshorn. Bei schwacher Vergrösserung fällt hauptsächlich die äussere Configuration auf: Der Durchsehnitt ist im Vergleich mit dem der anderen Seite anffallend klein - jedoch nicht auf die Art, wie wir dies im 2. Falle gesehen haben, wo die Volumsabnahme bauptsächlich auf die Rechnung der Zellenarmuth zu schreiben war; - hier ist das Verbältriss der Zellenschichten zu den Markfaserschichten ein normales, beide zeigen eine parallele Volumsabnahme. Es würde das Richtige treffen, wenn wir im ersteren Falle von Atrophie, in diesem Falle von Hypoplasie sprechen würden. 
Die Zellen der Pyramidenzellenschichte haben meistens normalen stychochromen Bau, nur ausnahmsweise finden wir auch solche, die dem ganglioklasten Typus angehören; noch relativ häufiger sind die Zellen mit feinkörnigem Zerfall und mit sklerotischer Degeneration. Eine Art Zwischenstelle unter diesen beiden letztgenannten Erkrankungen bildet eine andere Art der Degeneration, welche häufiger bei den polygonalen Zellen vorkommt, daher werden wir davon eine detaillirte Beschreibung dort geben. Diese Zellendegeneration wird durch Zerfall der Chromatinschollen und Verschwinden der Kerncontur charalterisirt. Zwischen den Pyramidenzellen finden wir nur vereinzelt degenerirte und welche vorkommen, liegen in der nnmittelbaren Nachbarschaft eines Gefässes. Vorherrschend ist der.kleinkörnige Zerfall, vereinzelt sind auch dunkel gefärbte sklerotische Zellen zu finden; während die ganglioklaste Erkrankung kaum durch einige Zellen vertreten ist.

Schwerere Veränderungen finden wir unter den polygonalen Zellen. Am auffälligsten ist eine Art der Degeneration, welche auch schon bei den Pyramidenzellenerkrankungen erwähntwurde, da aber diese hier häufiger und ausgeprägter vorkommt, gebe ich auch ihre Schilderung hier. Der Grundzug dieser Errrrankung ist der gleichmässig lörnige Zerfall des Chromatin und gänzliches Fehlen jeder Kerncontur. Das Zellenplasma färbt sich diffuse und ist mit kleinen punktförmigen tiefer tingirten Schollen dicht besät. Um das Kernkörperchen herum erscheint ein leerer untingirter oder nur sehr bleich gefärbter Hof, der conturenlos in die feinkörnige Masse des Zellleibes übergeht, so dass bei dem allmäligen Uebergang von einer Kerncontur nicht die Rede sein kann, vielmehr wird der Sitz des Kernes nur durch den Nucleolus angedeutet. Der Nucleolus selbst ist gedunsen, transparent und nur seine Contur bildet einen dunkleren Ring (Fig. 29).

Ein anderer Typus der Degeneration von den polygonalen Zellen wird durch die seröse Gedunsenheit charakterisirt (Fig. 30). Diese Zellen sind auffallend gross, ihr stychochromer: Bau ist annähernd normal, jedoch ist die ganze Färbung, auch die der Chromatinschollen, wie ausgelangt: das Plasma ist diffus blass gefärbt; stellenweise sitzen am Zellenrande grosse, bläschenähnliche Vacuolen.

Ausser diesen finden wir sehr häufig unter den polygonalen Zellen den ganglioklasten Degenerationstypus; jedoch werden die einzelnen Zellen von den Astrocyten nur in mässiger Anzahl angegriffen.

Die ovoiden Zellen der Pallisadenschichte haben meistentheils normales Verhalten, nur einzelne Inseln finden wir erkrankt. In diesen Inseln macht die Pallisadenschichte den Eindruck, als wenn die sonst in radiärer Richtung geordneten Zellen zusammengewühlt wären; dementsprechend hat ein grosser Theil der Zellen, da sie wegen der veränderten Raumverhältnisse den bipolaren Ursprung ihrer Fortsätze verloren haben, keine ovoide Form mehr, vielmehr haben sie eine polygonale Form angenommen (Fig. 31). Während an den geordneten Stellen derZellenschichte keine erkrankten Zellen zu finden sind, finden wir in den zusammengewühlten Inseln vielfach degenerative Formen. Von vielen Zellen ist nur mehr der. Kern übrig geblieben, an welchem 
nur kleine Fetzchen als Reste des körnig zerfallenen Zellleibs zu finden sind. In vielen. Zellen ist der Kern diffus gefärbt, ist entschieden gedunsen; in wieder anderen gedunsenen Zellkernen sitzen neben dem Nucleolus ansehnlich grosse Vacuolen; bei wieder anderen Zellen ist der Kern in Spaltung begriffen, ja wir finden in einer Zelle zwei gesonderte Kerne, die nur mehr von den Kernkörperchen als solche agnoscirt werden können. Diese erkrankten Inseln der Pallisadenschicht sind kaum reicher an Gliazellen als die übrigen Partien.

Wenn wir den histologischen Befund der Ammonshörner bei diesem Falle zusammenfassen, so finden wir die beiderseitigen Hörner in verschiedenem Grade erkrankt.

Das voluminösere rechte Horn weist eine reiche Gefässneubildung und Gliazellenvermehrung auf. Die Degeneration der zelligen Elemente ist am bèdeutendsten in der Pallisadenschichte, welche schon beim Schneiden sich als rissig herausstellte. Die Erkrankung ist in der Gliomatose einzelner Inseln zu suchen, zu der sich eine starke Vascularisation gesellt. Die Zellendegeneration trifft hauptsächlich die Kerne; selbe sind geschrumpft, dunkel gefärbt und ihre Kernkörper sind grösstentheils verschwunden.

Geringer ist die Degeneration der polygonalen Zellen; bei diesen ist stellenweise ein an Glastrümmer erinnernder Zerfall des Chromatins aufgefallen, daneben finden wir vereinzelt Anfangsstadien der ganglioklastischen Veränderung.

Am geringsten erkrankt ist die Pyramidenzellschichte, die mit Ausnahme einiger weniger geschrumpften und ganglioklastischen Formen normal gefunden wurde.

Bei dem linken Ammonshorne ist seine Kleinheit schon makroskopisch aufgefallen; bei schwacher Vergrösserung haben wir kaum eine Vermehrung der Blutgefässe und Gliazellen.

Die Pyramiden- und polygonalen Zellen weisen reichlich degenerative Formen auf, von denen die Mehrzahl dem sklerotischen und ganglioklastischen Typus angehört. Eine, schon bedeutendere Degeneration findet sich bei beiden Zellenformen vor, im Bilde des diffus gefärbten, gleichmässig gekörnten Zerfalles und Verschwinden der Kerncontour; ausserdem haben wir bei den polygonalen Zellen die seröse Gedunsenheit kennen gelernt.

Entsprechend dem Befund der anderen Seite, finden wir auch in der linksseitigen Pallisadenschichte nur eine fleckenweise Erkrankung; jedoch fehlt auf dieser Seite die mächtige Gefässproliferation und Gliawucherung; auch sind hier die Kerne, im Gegensatz zu der Schrumpfung der anderev Seite, gedunsen, zeigen Vacuolenbildung; stellenweise sind 
sie in Spaltung begriffen, - und all dies ist begleitet mit dem frühzeitigen kömigen Zerfall der Zelle.

\section{Beobachtung:-}

G. A., 34 Jahre alter Mann, ohne Beschäftigung. Anamnestische Daten sind sehr lückenhaft. Nur so viel ist zu eruiren, dass er seit Geburt taubstumm ist und sehr häufig an epileptischen Anfällen litt. In letzterer Zeit kamen diese Anfälle immer öfter: am 15. Märr 1896 wurde er wegen seines aggressiven Verhaltens in die psychiatrische Klinik aufgenommen. Seit seiner Aufnahme ist der Patient continuirlich in Status epilepticus; bei rascher Abnahme der Körperkräfte bekam er am 4. Tage eine hypostatische Pneumonie und erlag derselben am folgenden Tage. Bezüglich seiner epileptischen Anfälle sei zu bemerken, dass die motorischen Symptome sich meistens nur anf die rechte Körperhälfte beschränken, sich aber bei einzelnen sehr heftigen Anfällen auch auf die linke Körperseite ausbreiten. Diese Einseitigkeit der Muskelkrämpfe war auch an dem, dem Tode vorausgehenden Status epilepticus zu constatiren.

Von dem in der Klinik aufgenommenen Status praesens ist hervorzuheben das Zurückbleiben in der Entwickelung, in Folge dessen sein ganzer physischer und psychischer Habitus dem eines 13-14jährigen Buben gleichliommi. Bei der allgemeinen körperlichen Zurückgebliebenheit fällt auf, dass die rechtsseitigen Gliedmaassen im Wachsen früher Halt machten, insbesondere die obere Extremität; selbe war atrophisch und spastisch-paretisch; zeigte auch lebhafte, gesteigerte Reflexe. Ausser diesen Symptomen der Hemiplegia infantilis sei zu erwähnen, dass an der Zunge viele frische und alte Narben zu finden waren.

Bei der Obduction zejgte sich die Leptomeninx überall verdickt; es fanden sich in der linken Hemisphäre einige kleinere, im linken Temporallappen aber ein grosser, in die Tiefe bis zum Thalamuskern greifender gelber Erweichungsherd. Der linke Sejtenventrikel ist besonders stark ausgedehnt, der Ependymüberzug verdickt, lederartig; das Hinterhorn stark verlängert. Der línksseitige Plexus choroideus ist myxomatös degenerirt, bildet einen taubeneigrossen, unregelmässigen Knoten, welcher stellenweise aus sulziger Masse bestcht, in anderen Theilen wieder unter dem Messer knirschende Kalkconcremente und sklerotische Gefässe enthält. Das linke Ammonshorn ist in allen Dimensionen viel kleiner, als der rechte; fühlt sich härter an, ist auffallend reich an Gefässen und ist stark injicirt. Sämmtliche Gehirnarterien sind skierotisch.

\section{Mikroskopischer Befund.}

Rechtes Ammonshorn. Bei schwacher Vergrösserung finden wir keine auffallende Veränderung, höchstens fällt die Hypertrophie jenes Gliageflechts auf, welches, von der Fissura hippocampi entspringend, den Gyrus hippocampi vom Gyrus dentatus trennt; diese Hypertrophie ist von dem enormen Reichthum an Astrocytenkernen bedingt, welche in diesem Gliastrang (Kiel- 
strang, Weigert) stellenweise ganze compacte Massen bilden (Fig. 32). Eine ähnliche Vermehrung der Astrocyten finden wir an der ganzen Ventrikeloberfläche des Ammonshornes; in Folge dessen ist auch die tangentiale Gliaschicht verdickt.

Bei starker Vergrösserung weisen die ovoiden Zellen der Pallisadenschichte ein normales Verhalten, und nur unter den Pyramiden- und polygonalen Zellen finden wir vereinzelt auch degenerative Zellenexemplare. Je mehr wir in der Schnittserie dem Kopfende des Ammonshorns näher kommen, desto zahlreicher sind die erkrankten Zellen zu finden.

Unter den degenerativen Formen der Pyramidenzellen ist die Sklerose überwiegend, selbe bieten jedoch ein rom Gewöhnten differentes Bild. Die Zellen sind im Allgemeinen geschrumpft, ihre Ränder sind gelkerbt; an Stelle von strychochromem Bau finden wir homogene, mehr weniger dunkle Färbung, ausserdem in überwiegender Zahl der sklerotischen Zellen eine gleichmässige, feine Körnelung. Die Zellenkerne sind der Norm nach kleiner, färben sich viel dunkler, als der Zellleib, sind homogen gebaut. Kernkörperchen sind nur bei einigen wenigen sicher aufzufinden, bei anderen weist nur eine dunkler schattirte Partie des Kernes auf das Vorhandensein eines Nucleolus (Fig. 33). Einzelne sklerotische Zellen von ähnlichem. Typus haben nur den dunkel gefärbten, homogenen Kern normal beibehalten, der Zellleib hingegen ist feinkörnig zerfallen und nur einige Körnchenansammlungen lassen uns die Grenzen der ehemaligen Zelle ahnen. Die Dendrite dieser geschilderten sklerotischen Zellon sind stark tingirt, öfters zerbröckelt. Ausser diesen besonderen Formen finden wir auch die gewöhnliche Sklerose (starke Färbung und Schrumpfung) vertreten.

Die polygonalen Zellen haben meistentheils normalen stychochromen Bau; ihre degenerirten Formen kommen theils den bei den Pyramidenzellen beschriebenen sklerotischen Veränderungen gleich, theilweise wieder finden. wir einen anderen Typus, welcher mit der Gedunsenheit des Kernes einher-geht; das Kernkörperchen ist entweder geschrumpft oder es fehlt gänzlich; der ganze Kern ist ein wenig gekörnt oder ist homogen und bläschenartig. -Bei manchen Zellen lugt der blasse Kern an einer Seite des Zellleibes hervor .(Fig. 34). Andere Zellen färben sich gleichmässig blass und zeigen in toto . eine feine Körnelung. Ihre Kerne sind im Ganzen quasi anfgelöst im Zellleibe und fallen nur mehr durch einzelne, blass angedentete Bogensegmente der Kerncontour vom übrigen Plasma auf (Fig. 34).

Linkes Ammonshorn. Bei schwacher Vergrösserung sehen wir die starke Vermehrung der Gliazellen und den Gefässreichthum der Schnitte. Die Ventrikeloberfläche ist zerfetzt, der Ependymbelag ist verschwunden; an seiner Stelle sitzt eine kleinzellige Infiltration und eine amorphe Dentritusmasse. Schon bei dieser Vergrösserung fällt der Defect der Nervenzellenschichten auf; die Pyramidenzellenschicht ist stellenweise schütter geworden und weist daselbst vermehrte Astrocyten auf; in der Bucht der polygonalen Zellen klaffen ganze leere Flecke. Die Bucht der Pallisadenschicht ist im Allgemeinen zellarm; in der Pallisadensehicht selbst fehlt die regelmässige, parallele Anordnung 
der Zellen, es wimmelt von vermehrten Astrocytenkernen und von radiär verlaufenden, stark injicirten Gefässen.

In der Pyramidenschicht finden wir kaum welche normal gebaute Zellen; sie stehen meistens auf verschiedener Stufe der sklerotischen Degeneration. Es überwiegen zwei skierotische Typen (Fig. 35); bei dem einen ist die Zelle diffus gefärbt, hat kaum eine Körnelung; deı Kern hat seine scharfe Contour verloren und wir sehen nur einen central gelegenen, helleren, ovalen Fleck, von welchem das Kernkörperchen scharf hervortritt. Die Ränder der Zello sind glatt; die ganze Zelle ist kleiner, die. Fortsätze sind stark gefärbt und können längere Strecken hindurch verfolgt werden. Bei dem zweiten sklerotischen Typus ist die Körnelung der Zelle ausgesprochener; der Kern scharf contourirt und unregelmässig geschrumpft; wirft viele dunkel gefärbte Falten. Diesen Typus finden wir oft combinirt mit dem ganglioliastisehen, indem an der Basis der so erkrankten Pyramidenzelle Mulden und umschriebene Vacuolen sitzen, in denen Astrocytenkerne zu finden sind. Die Pyramidenzellen zeigen bei hoher Stufe der Sklerose (Fig. 36) schon gar lieine Structur; sie sind gleichmässig dunkel gefärbt, die Fortsätze dünn, tief gefärbt und zerbröckelt. Für die Erkrankung der Pyramidenzellen ist im Allgemeinen charalkteristisch, dass, während die Sklerose nur zerstreut und kaum sichtbar, die Zahl der Zellen vermindert ist, ist an jenen Stellon, wo schon bei schwacher Vergrösserung die Verminderung der Zellen auffällt, die ganglioklastische Form die vorherrschende; daselbst sind die Flecke stark vascularisirt und von Astrocyten überfluthet. Diese schütteren Stellen der Pyramidenschicht verdanken nicht der Aplasie, sondern der Destruction ihren Ursprung. Dies beweisen uns die vielen Zellentrümmer, welche wir hier finden, und welche nur mehr durch ihren Zusammenhang mit einzelnen Dendriten als Zellenreste erkannt werden.

Aehnliche, jedoch schon vorgeschrittenere Formen finden wir in der polygonalen Zellengruppe der Fascia dentata. Schon bei schwacher Vergrösserung erkannten wir die auffallend geringe Zahl dieser Zellen und einzelne leere Inseln. Wo wir mehrere Ganglienzellen nebeneinander finden, dort ist ausser einigen, normalen stychochromen Bau aufweisenden Zellen die Mehrzahl auf verschiedener Stufe der Sklerose; unter diesen finden sich ausser den einfach geschrumpften, structurlosen und dunkel gefärbten Exemplaren auch solche, bei denen einige grössere Chromatinschollen den tigroiden Bau der Zelle noch aufrecht erhalten; jedoch ist die Zelle auf einer Seite zerfetzt, ausgebröckelt; an dieser Seite lugt dann der nackte Kern heraus; derselbe hat blos sein Kernkörperchen beibehalten, sonst ist seine Körnelung verloren gegangen und nur durch seine scharfe Contour hebt er sich aus dem Zellleib als eine leere Scheibe hervor (Fig. 37).

Demgegenüber sehen wir an den polygonalen Zellen, die sich vereinzelt in den leeren Inseln vorfinden, meistens die ganglioklaste Erkrankung; dies entspricht auch dem Astrocytenreichthum und der stark injicirten reichen Vascularisation dieser zellenarmen Partieen. Von dem bisher beschriebenen ganglioklastischen Typus finden wir zweierlei differirendes Verhalten. Schon 
bei den bisher geschilderten ganglioklastischen Formen haben wir gesehen, dass der normale stychochrome Bau der Zelle mehr weniger durch eine feine Körnelung ersetzt wird; die Kerne hingegen haben ihre normalen Contouren und normale Körnung bewahrt, welch letztere in dem Punktkranz um den Nucleolus herum am meisten ausgeprägt ist. (Siehe 1. Beobachtung). Dem widersprechend sind bei diesen ganglioklastischen Formen die Zellen wie ansgelaugt; die Körnung ist verschwommen, die Kerncontouren heben sich kaum hervor; der Kern ist vollkommen homogen geworden. Der zweite L'mstand ist der, dass die Astrocytenkerne sich nicht so tief in den Zellleib eingebohrt haben, vielmehr um die Zelle und ihre Dendrite herum wimmeln, daher sie anstatt Ganglioliasten treffender Trabantzellen genannt werden könnten. Während wir bei den bisher beschriebenen ganglioklastischen Formen normale, nur an Zahl vermehrte Astrocytenkerne gefunden haben, sehen wir hier, dass die die Ganglienzelle umgeben den Gliakerne de norma viel kleiner sind, dicht gekörnt, und keinen grösseren, dem Kerniörperchen der normalen Astrocyten entsprechenden Kern haben (Fig. 37). Die Dendritfortsätze dieser jetzt be: schriebenen Zellen färben sich auffallend intensir, sie zerbröckeln auch, und so sehen wir an ihnen eine Uebergangsform zur Sklerose.

In der Pallisadenschichte sind einzelne patbologisch veränderte Flecke, welche immer mit der starken Vascularisation derselben Stellen zusammenfallen; hier sind die Gefässe stark injicirt, in ihrer Nähe sind die Astrocyten an Zahl vermehrt. In diesen erkrankten Partien prävaliren die Kernveränderungen. (Fig. 38.) Die Kerne haben ihre Körnung verloren und sind diffus, verschieden intensiv gefärbt, sogar bleiben sie bei einigen Zellen gänzlich untingirt. In den meisten Kernen ist noch der Nucleolus vorhanden, obwohl er bei manchen bereits verschwunden ist. Bei einigen dieser: Zellen ist der Kern gedunsen, dann ist auch die Zelle selbst etwas grösser, als normal; andere Kerne sind in Theilung begriffen, so dass in einer Zelle auch zwei Kerne mit gesonderten Nucleolen sich finden. In diesen erkrankten Partien haben die Zellen wohl keine normale stychochrome Structur; die meisten sind theilweise oder in toto diffus gelärbt; bei einigen Zellen ist der Zellkern allein geblieben, an welchem nur Fetzchen des destruirten Zellenplasmas sitzen.

Wenn wir den mikroskopischen Befund dieser 4. Beobachtung überblicken, finden wir beide Ammonshörner verschiedentlich erkrankt.

Das rechte Ammonshorn, welches sich bei der Section als relativ gesundes erwies, hat die meisten Zellveränderungen in den Pyramiden- und polygonalen Zellen. Der herrschende Typus ist eine besondere Art der Sklerose, die durch die Kernschrumpfung und intensivere Färbung des Kerns als das Plasma sich charakterisirt; bei einer anderen Erkrankungsform ist der Kern gedunsen, hat seine scharfe Contour verloren. Das Kernkörperchen ist bei Vielen ganz verschwunden. Bei diesem Ammonshorn haben wir die bäufigste Form der epileptischen Zellveränderungen, nämlich die ganglioklastische nicht xertreten gefunden; in Einklang damit waren auch die Astrocyten nicht vermehrt, einzig nur in der subependymalen Schichte war dieses der Fall; die Vascularisation war nicht reicher, als normal. 
Das linke Ammonshorn imponirte schon bei der Obduction als mehr sklerotisch. Dementsprechend sind die mikroskopisch nachweisbaren Veränderungen dieser Seite auch ausgesprochener. Das Ammonshorn im Ganzen, insbesondere jedoch in einzelnen Inseln zeigt eine reiche Gefässneubildung und Gliomatose. Anch die Ganglienzellenveränderungen dieser Flecke übertreffen diejenige anderer Partien.

Die Pyramidenzellenschicht ist zellenarm, hat kaum irgendwelche gesunde Zellen; überwiegend ist jene Form der Sklerose, bei welcher sich der Zellleib diffus färbt, der Kern jedoch ist geschrumpft, die Kernmembran zerknittert: An den stärker vascularisirten Stellen sind die Pyramidenzellen an Zahl vermindert, unter ihren Degenerationsformen tritt die ganglioklastische immer mehr in den Vordergrund. Bei einigen Zellen combinirt sich dieser Typus mit der Sklerose, bei anderen hingegen zeigt er sich als eine selbstständige Erkrankungsform. Die Degeneration der polygonalen Zellen ist identisch mit denen der Pyramidenzellen; nur jene Variante der ganglioklastischen Veränderung ist zu erwähnen, deren Färbung quasi ausgelaugt ist, ihre zerbröckelten Dendriten erinnern an die einfache Sklerose; endlich die Ganglioklasten haben kleinere Kerne und sie umgeben nur die Zelle, bohren sich jedoch in selbe nicht hinein (Trabanten).

In den einzelnen hypervascularisirten Stellen der Pallisadenschichte finden wir verschiedene Erkrankungen der Kerne: meistens die diffuse Blähung, Theilung, endlich das Verschwinden des Kernkörperehens; der Zellleib erkrankt auch, indem er den stychochromen Bau verliert; an vielen Stellen liegen nur mebr Fetzchen von dem Zellkörper an.

Die mikroskopische Untersuchung der Ammonshörner in diesen 4 Fällen von Epilepsie hat zu verschiedenen Resultaten geführt. Von diesen Verschiedenheiten bleibt uns als einzig Beständiges, dass nämlich die Ammonshörner in jedem Falle sicher erkrankt sind; dabei sehen wir die Veränderungen einestheils an den Nervenzellen, anderentheils fällt uns jedoch der Zusammenhang dieser Zellenerkrankungen mit Veränderungen in dem Gliagewebe und mit dem Verhalten der Blutgefässe auf.

Wenn wir das Untersuchungsergebniss ordnen wollen, ganz abgesehen davon, in welchem Falle es gefunden wurde, so können wir eine Graduation bezüglich des Erkrankungsgrades und der Natur der pathologischen Veränderungen aufstellen.

Der mikroskopisch festgestellte Grad der pathologischen Veränderungen ist meistens proportionirt den bei der Obduction gefundenen makroskopischen Erkrankungen und ist im Allgemeinen am ausgesprochensten bei jenen Ammonshörnern, die bei der Section selerotisch sich erwiesen. Doch können wir durchaus nicht behaupten, dass die Proportion der makroskopischen und mikroskopischen Veränderungen streng regelmässig wäre: die höchsten Veränderungen haben wir in dem scle- 
rotischen Ammonshorn des ersten Falles gesehen, wo doch die Sclerose im zweiten Falle auf einer viel höheren Stufe stand. Auf Grund meiner Untersuchungem behaupte ich, dass der normale Sectionsbefund irgend eines Ammonshorns noch nicht beweisend ist für seine histologische Intactheit, da ich bei mehreren ohne äusserlich sichtbare Veränderungen feine mikroskopische Destructionen festgestellt habe.

Von den histologischen Veränderungen habe ich schon erwähnt, dass sie einen constanten Nexus zwischen dem Verhalten des Nervenstützgewebes und der Gefässe aufweisen.

Eingehender haben wir uns nur mit den Erkrankungen der Ganglienzellen beschäftigt, bei denen morphologiseh 3 verschiedene Typen zu constatiren sind; dabei können wir bei jedem einzelnen mehrere Untertypen unterscheiden, Trotz dieser morphologischen und pathologischen Verschiedenheiten können wir sämmtliche Zellenveränderungen auf einige Grundformen zurückführen.

Von den einzelnen Zellenerkrankungsformen müssen wir annehmen, dass sie den ephemeren Zustand von dem Destructionsprocess der Zellen zur Zeit des Todes aufweisen, d: h. mit einem klinischen Ausdruck, dass sie gleichwerthig sind mit dem Status praesens eines Erkrankungsprocesses; in Folge dessen wäre es lehrreich, die einzelnen Degeneratiousformen in ihrem Ursprung und ihrer Entwickelung zu beobachten; dies ist jedoch an Sectionsmaterial nur approximativ durchführbar, und so wäre die Untersuchung der Entwickelung der Destructionsformen sowie deren Zusammenhang unter einander eher die Aufgabe der experimentellen Pathologie. Der Zweck dieser meiner Arbeit ist nur die Description; trotzdem habe ich in den Fällen, wo einzelne Zellendegenerationsformen es wahrscheinlich machten, dass sie nur verschiedene Stufen eines Processes seien, dies bei der detaillirten Beschreibung gieich bervorgehoben. Hier will ich nur mehr die wichtigsten Typen der gefundenen Erkrankungsformen aufzählen und werde einzelne dazugehörige allgemein gültige Bemerkungen anknüpfen.

Der Häufigkeit nảch am stärksten ist vertreten die Sclerose. Im Allgemeinen können wir diese Erkrankung so beschreiben, dass die Zelle kleiner wird und mehr von. dem angewendeten Farbstoff aufnimmt. Neben diesem allgemeinen Charakter bieten die hierher gehörigen Zellen ein verschiedentliches histologisches Bild: die stychochrome Structur ist mehr weniger normal oder aber ist das Chromatin in grobe Schollen zusammengebacken, ein andermal ist es in feine Körner zerfallen; die Zellencontouren bald gekerbt, bald wieder wie ausgebröckelt oder sehen wie zerfetzt aus, - der Kern ist bald normal mit scharfen Contouren, bald wieder hat ex das normale Aussehen verloren: die 
Contouren sind verwischt oder gänzlich verschwunden; in anderen Fällen schrumpft der Kern und seine Membran wirft Falten; in einzelnen Fällen färbt sich der Kern intensiv und das Kernkörperchen verschwindet; die Dendritfortsätze sind in einzelnen Formen normal, schwach gefärbt, in anderen färben sie sich stark und zerbröckeln.

An der zweiten Stelle der Häufigkeitsscala steht die ganglioklastische Degeneration. Im Grossen und Ganzen können wir sie so beschreiben, dass um die Zelle herum viele Astrocyten sich ansammeln, welche entweder der Zelle einfach anliegen oder in muldenförmiger Aushöhlung sitzen, oder aber befinden sie sich in vacuolenförmigen Höhlen. (Bei der epicritischen Beurtheilung dieses Befundes muss ich bemerken, dass ich die Höhlen, in denen die Astrocytenkerne sitzen, wissentlich als "vacuolenförmige" bezeichnet habe, da es doch gar nicht erwiesen ist, dass selbe wirkliche Höhlen sind; es wäre doch leicht denkbar, dass es Durchschnitte von Buchten sind, welche von Regionen oberhalb oder unterhalb des Schnittes eingedrungen und welche so quer durch das Microtommesser getroffen, als gänzlich abgeschlossene Höhlen imponiren; auch Autor kann es nicht verschweigen, dass er dieser Meinung ist.) Neben dem pathognomen Charakter der ganglioclastischen Erkrankung zeigt die feinere Structur dieser Zellen ein verschiedentliches Bild. Nur das Eine ist zu betonen, dass nämlich diese Zellen nie normale Structur aufweisen, selbst in Spuren äusserst selten (Fig. 19). Abgesehen davon sind die Zellen normal gross, oder sind geschrumpft oder auch vergrössert; die Zahl der in die Zelle gedrungenen Astrocyten ist gering oder gross; sie sitzen oberfiächlich oder haben sich mehr in die Tiefe eingebohrt. Das Chromatin dieser Zellen ist feinkörnig zerfallen oder ist in grössere Schollen versehmolzen, ein andermal ist es verschwunden und gibt einer homogenen Färbung Platz. Die Zellkerne bleibeu normal oder sind geschrumpft oder verschwirrden auch gänzlich; in anderen Fällen befinden sie sich in Theilung begriffer. Die Dendritfortsätze sind bei diesem Typus entweder normal oder färben sich intensiver und sind zerbröckelt.

Der Zahl nach die dritte Stelle nimmt jene Degenerationsform ein, die wir körnigen Zerfall nennen. Seinen pathognomen Charakter gibt ihm die feinkörnige Form des Chromatin, weiterbin der Umstand, dass der Zellkern seine Selbstständigkeit verlor; seine Grenzen sind verschwunden oder sind nur mehr in Spuren aufzufiuden. Auch diese Form hat einige Varianten: die Zellenconturen sind normal oder zerfetzt oder fehlen anch gänzlich (Fig. 27); die Körner sitzen inmitten eines ungefärbten oder homogen tingirten Hofes; das Kernkörperchen ist normal oder gedunsen oder geschrumpft, bald ist es wieder ganz 
verschwunden; die Körnelung ist weit in den Dendriten hinein zu verfolgen, oder aber es hört dieselbe bald bei der Dendritwurzel auf.

Am seltensten waren die serös gedunsenen Formen aufzufinden. Ihr pathognomer Zug ist die Vergrösserung der Ganglienzellen; dabei ist die Färbung der Zelle mehr oder weniger verwaschen, als wie wenn sie ansgelaugt wäre; das Kernkörperchen ist ebenfalls gedunsen, färbt sich wenig, und nur seine Contouren sind dunkler. Neben diesem stabilen Charakter ist die stychochrome Structur mehr oder weniger normal oder sind die einzelnen Chromatinschollen in feine Körnchen zerfallen; ein andermal ist der tigroide Charakter verschwunden, und so ist der Zellleib von feinen Pünktchen erfüllt; die Kerncontouren bleiben scharf oder sind verschwommen; in der Zelle oder an deren Peripherie sitzen homogen gefärbte blasenförmige Vacuolen.

Einen weitläufigen Zusammenhang zwischen den Zellendegenerationstypen und den übrigen pathologisch-histologischen Befundeu des Organs finden wir nur bei der ganglioklastischen Erkrankung. Wir sehen nämlich, dass dieser Degenerationstypus sich immer combinirt mit der Blutgefässneubildung, mit einer starken Injection und der Vermehrung der Gliazellen. Hier wäre die Frage zu beantworten, welche ich schon bei der Beschreibung berührt habe, ob nämlich diese Gliahypertrophie schon $a b$ ovo besteht, oder ob sie erst im Verlaufe der Epilepsie sich entwickelt. Gegen das späte Auftreten spricht der epitheliale Ursprung des Gliagewebes, weiterhin der Umstand, dass wir nirgends in Theilung begriffene Astrocytenkerne gesehen haben. Ihre Vermehrung muss aber nicht unbedingt auf Zellentheilung beruhen, da es doch möglich wäre (zwar sprechen unsere Kenntnisse vom Gliagewebe dagegen), dass sie aus Wanderzellen auf neoplastischem Wege sich bilden, wie wir dies bei dem Bindegewebe sehen. Diese Auffassung widerspricht unseren entwickelungsgeschichtlichen Erfahrungen, jedoch viele Umstände befürworten sie: 1. Wir haben eine Variante der ganglioklastischen Veränderung gesehen, bei der die Astrocytenkerne viel kleiner als in der Norm waren, keine Kernkörperchen hatten, als wenn sie Wanderzellen wären. 2. Die Vermehrung der Astrocyten ist immer am stärksten den Gefässen entlang. 3. Von jenen Astrocyten, welche wie Trabanten die Zelle umgeben, noch viel mehr aber von jenen, welche sich in den Zellkörper eingebohrt hatten, ist doch schwer anzunehmen, dass sie immer dort gewesen waren; noch schwerer wäre es aber, uns vorzustellen, dass die angenagten Ganglienzellen immer so gewesen wären; oder, dass nicht die Astrocyten die Nervenzellen befallen hätten, sondern die Ganglienzelle hätte sich durch Theilung oder durch noch umbekannte Neubildung in der Mitte eines Astrocytennestes 
entwickelt. 4. Der Umstand, dass an einer vorgeschrittenen Stufe der ganglioklastischen Erkrankung die Nervenzelle als solche aufhört zu existiren, und nur Trümmer zurückbleiben, beweist die destructive Natur dieses Processes unanfechtbar; es ist nicht vorzustellen, dass bei einer solchen, von Geburt aus bestehenden Gliomatose, an der die Ganglienzellen leiden, dieselben noch immer auf verschiedener Stufe der Degeneration stagniren würden, und dass sie schon lange nicht verschwunden wären, da sie schon in Folge ihrer speciellen Entwickelungsconjuncturen dafür prädestinirt waren. 5. Endlich wäre noch die Meynert'sche Auffassung zu berücksichtigen, nach welcher die Degeneration des Ammonshorns nicht die Ursache der Epilepsie sei, vielmehr deren Folgezustand; diese Auffassung würde ja auch dafür sprechen, dass wir es hier mit den Folgen eines erst später aufgetretenen gliomatösen Zellenschwundes zu thun haben. Ja an den selbstständig aufgetretenen Gliomen sehen wir, dass, wenn wir auch hypothetischerweise einen früher latenten krankhaften Keim annehmen müssen, doch kommt es nur später zu einer hypertrophischen Zellentheilung. Aus den mikroskopischen Bildern der ganglioklastischen Degeneration wurde Autor zu der Meinung geführt, dass die Astrocyten die Ganglienzelle wie eine Burg angreifen und selbe darunter schnell zu Grunde geht; dafür spricht das gänzliche Fehlen der normalen stychochromen Structur der angegriffenen Zellen, weiterhin der Umstand, den wir beobachtet hahen, dass nämlich an bestimmten Inseln, die hypervascularisirt and hypergliomatös erscheinen, die Zahl der Ganglienzellen sehr gering ist, und die noch bestehenden zeigen alle die ganglioklastische Degeneration; dem entgegengesetzt an Stellen, die an Gefässen und Astrocyten relativ ärmer sind, hat die Zahl der Nervenzellen weniger abgenommen, und der herrschende Degenerationstypus derselben ist nicht mehr der ganglioklastische, sondern der sklerotische.

Aus den vorgenommenen Untersuchungen erhellt eine ziemlich consequente Relation zwischen dem makroskopischen Befund der Ammonshörner und deren vorherrschenden Degenerationstypen. Wir sahen, dass die schon bei der Obduction sich als sklerotisch erweisenden Ammonshörner ausser einer bedeutenden Gliomatose meist an der ganglioklastischen und sklerotischen Degeneration ihrer Ganglienzellen leiden, während bei den normal grossen und normal consistenten oder erweichten Ammonshörnern neben den übrigen Degenerationsformen auch der körnige Zerfall und die seröse Gedunsenheit Platz greifen. Was den allgemeinen Entwickelungsgrad oder die Intensität der Zellenveränderungen betrifft, abgesehen von deren pathologisehen Qualitäten, 
so sehen wir, dass die schwersten Zellenerkrankungen bei dèr makroskopisch constatirbaren Sklerose der Ammonshörner zu finden sind, wir haben ja unter solchen Conjuncturen wiederholt Stellen gefunden, wo ein ganz beträchtlicher Theil einer Nervenzellenschichte auch spurlos verschwunden war.

Als Schlussresultat will ich die wichtigsten pathologischen Veränderungen der epileptischen Ammonshörner im Folgenden zusammenfassen:

1. Bei der Obduction sind beide Ammonshörner oder das eine kleiner als normal und consistenter (Sklerose).

2. Mit dieser Veränderang paart sich eine reiche Gefässneubildung und Hypergliomatose.

3. In einzelnen Zellengruppen, insbesondere in jener der Pyramidenzellen, weniger in der der polygonalen Zellen, ist fleckenweise gänzlicher Zellenschwund zu constatiren.

4. In diesen zellenleeren Inseln sind die Gliazellen besonders vermehrt.

5. Mit der Hypergliomatose geht die ganglioklastische Zellenerkrankung einher.

6. Die Sklerose der Zellen.

7. Der körnige Zerfall der Zellen.

8. Die seröse Gedunsenheit der Zellen:

Für weniger typisch halte ich bei Epilepsie die Erweichung des Ammonshornes, da sie einestheils viel seltener rorkommt, zweitens ist sie auch nicht scharf localisirt auf dem Ammonshorn, sondern verbreitet sich auf dessen ganze. Umgebung. Dem entgegen finden wir sklerotische Ammonshörner bei Epileptikern, bei denen sonst im ganzen centralen Nervensystem kein zweiter sklerotischer Herd besteht. Ich fand bei meinen Untersuchungen, dass die zwei typischen Zellendegenerationsformen, nämlich die ganglioklastische und die sklerotische verbunden sind zu der allein typischen groben Erkrankung der Ammonshörner, nämlich zu der Skierose, und es scheint mir, dass alle die anderen groben und feinen Erkrankungen bei genuiner Epilepsie nur eine accidentelle Rolle spielen.

Auf Grund meiner Untersuchungen halte ich die typischen Veränderungen der Ammonshörner bei Epilepsie (nämlich die Sklerose) für entzündlich, dafür spricht ja nicht bloss das Verhalten der Blutgefässe and des Nervenstützgewebes, sondern auch die in den meisten Fällen vorhandene Ependymitis und Hydrocephalus internus. Diesen entzündlich encephalitischen Process halte ich für einen sehr langsamen; seine Folge ist die bei der Obduction und der mikroskopischen Untersuchung 
aufgefundene sklerotische Atrophie, welche als gleichbedeutend zu betrachten ist mit der bindegewebigen Atrophie anderer chronisch entzündeter Organe.

\section{Erklärung der Abbildungen (Taf. XI. und XII.).}

Fig. 1. Amyloiddegeneration.

Fig. 2. Hypertrophie der tangentialen Gliaschicht.

Fig. 3. Gesammtüberblick des Zellenschwundes im Falle I. bei Lupenvergrösserung.

Fig. 4, 5 und 6 weiterhin.

Fig. 5-16. Zellendegenerationstypen des rechten Ammonshornes bei demselben Fall.

Fig. 18. Makroskopischer Vergleich der beiden Ammonshörner in Beobachtung 2.

Fig. 19, 20. Zellentypen des rechten Ammonshornes in Beobachtung 2.

Fig. 21. Linkes Ammonshorn im selben Falle. Schwache Vergrösserung.

Fig. 22-24. Degenerirte Zellen desselben Ammonshornes.

Fig. 25. Makroskopischer Vergleich der beiden Hörner in Beobachtung 3.

Fig. 26-28. Zellen des rechten Hornes im selben Falle.

Fig. 29 und weiterhin.

Fig. 30, 31. Zellen des linken Ammonshornes in Beobachtung 3.

Fig. 32. Gliahypertrophie in dem rechten Ammonshorn (Beobachtung 4).

Fig. 33-34. Zellentypen derselben Seite.

Fig. 35-38. Zellen des linken Ammonshornes. (Dieselbe Beobachtung.)

Die mikroskopischen Bilder zeichnete ich nach Vergrösserungen mit der Zeiss'schen $2 \mathrm{~mm}$. Apochromatimmersion und 4 er Compensationsocular. 